\title{
GAIA Level 1 Assessment of Preterm Labor
}

National Cancer Institute

\section{Source}

National Cancer Institute. GAIA Level 1 Assessment of Preterm Labor. NCI Thesaurus. Code $C 127947$.

GAIA Level 1 Assessment of Preterm Labor is defined by three criteria: first, confirmed delivery of a fetus between 24 0/7 and 36 6/7 weeks gestation; second, greater than four uterine contractions per hour as determined by a tocodynometer OR transvag inal ultrasound during a two hour period; third, documented change in length or dilation of the cervix by physical examination, with clinical criteria obtained by digital examination, including: a) Cervical dilation of two centimeters or more at the internal os; b) Cervical length of one centimeter or less; c) greater than or equal to $50 \%$ effacement of the cervix. 